\section{Desenvolvimento local ou Migração? Uma reflexão sobre as alternativas para os jovens do semiárido brasileiro}

Resumo: Este trabalho tem como objetivo principal discutir a realidade da migração da mão de obra jovem, de uma comunidade localizada no semiárido brasileiro. Como metodologia para este trabalho utilizou-se: uma pesquisa bibliográfica em artigos científicos e pesquisa documental em materiais técnicos disponibilizados por órgãos públicos, para coletar dados primários utilizou-se a observação direta e a discussão em grupo focal com 12 jovens, realizada em janeiro de 2010 numa cidade do interior do estado da Paraíba no nordeste Brasileiro. Entre os resultados, pode se observar que o fenômeno das migrações traz conseqüências para as regiões de saída e chegada. Desta forma é importante observar o que este fenômeno significa para o desenvolvimento do local, se existem implicações para o futuro da região o fato da mão de obra jovem estar sendo utilizada em outra região. Ao que parece o dinheiro que retorna ou que é enviado pelos migrantes amenizam a situação durante um curto espaço de tempo, mas a perda de jovens resulta em um prejuízo muito maior para a cidade a médio e longo prazo, favorecendo a manutenção de estruturas arcaicas que tanto prejudicam a região.

\section{Local development or Migration? A reflection on the alternatives for young people in semi-arid regions of Brazil}

\begin{abstract}
The main objective of this essay is to discuss the reality of migration of young workforce from a community located in the semi-arid regions of Brazil. The methodology used for this essay was: a literature review in scientific articles and a documentary research on technical materials, made available by public organizations. In order to collect primary data, it was used direct observation and a discussion with a focused group of 12 young people, held in January 2010 in a city in the state of Paraiba, in northeastern Brazil. Among the results, it was noticed that the phenomenon of migration has consequences for the regions of departure and arrival, showing a complex reality with alarming rates of depletion of some small cities at certain times of the year. Another noticeable result is the money that returns or that is sent by immigrants. Those economic resources ease the situation for a short time, but the loss of young people brings about a much greater loss to the city, in the medium and long term, favoring the maintenance of archaic structures that have plagued the region so much.
\end{abstract}

Vinícius Claudino de Sá* José Geraldo Wizniewsky**

* Professor do Departamento de Administração da UERN, Doutorando do Programa de Pós Graduação em Extensão Rural da UFSM, com interesse em Gestão do Desenvolvimento.

** Programa de Pós Graduação em Extensão Rural - UFSM

\section{Palavras-chave:} Migração; Juventide; Desenvolvimento.

Key-Words: Migration; Youth; Development. 


\title{
Introdução
}

Ao longo da história do Brasil houve um crescente fluxo migratório interno. Vários foram os fatores que motivaram os deslocamentos internos. Entre eles pode-se destacar a importância do parque industrial paulista, que assumiu papel hegemônico na indústria brasileira na primeira metade do século XX. Neste período muitos migrantes se transferiram para a capital paulista, encontrando trabalho nas indústrias e atividades terciárias. Este trabalho tem como objetivo principal discutir a realidade da migração da mão de obra jovem, de uma comunidade localizada no semiárido brasileiro.

A região nordeste, em específico, apresenta uma forte emigração rural e desde os anos 40 , apresenta uma saída de sua população rural para áreas urbanas. Para Targino (1994) homens e muIheres migram a centros mais desenvolvidos, ocupando-se no setor de serviços como: vigias, porteiros, lavadores de carros, setor de limpeza em geral e construção civil. (MEDEIROS e MOREIRA, 2008)

Na década de 80, um fenômeno chamou a atenção dos pesquisadores.

\begin{abstract}
Há consenso entre os especialistas sobre a constatação de que, a partir dos anos 80 , ocorreram acentuadas transformações nos volumes, fluxos e características dos movimentos migratórios no Brasil, sintetizados num menor crescimento das metrópoles, numa maior predominância de migrações a curta distância e intraregionais, (PATARRA, 2003, p. 54)
\end{abstract}

Entretanto, atualmente é possível observar que as migrações temporárias, aquelas que acontecem em determinadas épocas do ano, ou em ocasiões especiais vem aumentando consideravelmente. Neste tipo de saída, o trabalhador passa longe da sua família alguns meses por ano, tempo em que trabalha geralmente com carteira assinada, garantindo no seu retorno o pagamento do salário desemprego, uma injeção de recursos para as famílias que passam a sobreviver de uma agropecuária basicamente de subsistência.

Vale a pena destacar que os grupos humanos que habitam o semiárido brasileiro apesar das inúmeras semelhanças entre si, podem divergir enormemente em alguns hábitos, estilos de vida e comportamentos, principalmente no aspecto que será estudado neste trabalho, que é o da migração de jovens, pois, os destinos, os locais de trabalhos, variam, e dentro de uma mesma família pode haver filhos que trabalham na construção civil, outros em restaurantes, e outros revendendo produtos de porta em porta.

Os fatores de expulsão são diversos e determinam o processo migratório. Através destes fatores são definidas as áreas onde se originam as migrações, pois eles, pode-se assim dizer, têm o papel de formar o exército de reserva de mão-de-obra.

\footnotetext{
Enquanto as áreas favorecidas acumulam vantagens, as áreas desfavorecidas sofrem um relativo empobrecimento. Para a população dessas últimas áreas, as oportunidades econômicas praticamente não existem. O nível de vida é baixo, os horizontes de futuro da população são reduzidos e sem expectativas de prolongá-los. (MEDEIROS e MOREIRA, 2008, p.5)
}

Para Silva (2006) apud Silva (2008) as realidades dos jovens ainda apresentam as pressões do consumo, onde:

Geografia Ensino \& Pesquisa, v. 17, n.1 p. $07-14$, jan./abr. 2013

Desenvolvimento local ou Migração? Uma reflexão sobre as alternativas para os jovens do semiárido brasileiro
Sem condições que Ihes permitam a satisfação de suas necessidades de consumo próprias: o clube, a motocicleta, a roupa, etc., os jovens acabam encontrando na migração do corte de cana-de-açúcar uma alternativa para a concretização de seus projetos pessoais de autonomia... (SILVA, 2008, p.4).

De modo a compreender melhor este processo, utilizou-se a seguinte metodologia: uma pesquisa bibliográfica em artigos científicos e material técnico disponibilizados por órgãos públicos, também serão apresentados dados coletados em observação direta e numa discussão de grupo 
focal com 12 jovens, realizada em janeiro de 2010 numa cidade do interior do estado da Paraíba no nordeste Brasileiro.

Para a distribuição dos capítulos organizou-se uma parte inicial com um referencial teórico para apresentar a região do semiárido brasileiro com algumas informações sobre o contexto histórico e geográfico, também se buscou apresentar algumas discussões sobre a migração e os processos migratórios e por fim, uma discussão sobre a juventude. A segunda parte ficou com a análise e apresentação dos dados e na terceira e última parte as considerações finais. Como pode ser visto a seguir.

\section{Referencial teórico}

\section{Delimitação e caracterização climática do semiárido brasileiro}

O semiárido brasileiro, atualmente com $969.589,4$ km², com1.133 municípios e uma população de 20.858.264 pessoas. Para definir o Grupo de Trabalho Interministerial formado em 2004 pelo Ministério do Meio Ambiente - MMA e pelo Ministério da Integração Nacional - MI, baseou-se em três critérios técnicos:
a) precipitação pluviométrica média anual inferior a 800 milímetros;
b) índice de aridez de até 0,5 , calculado pelo balanço hídrico, que relaciona a precipitação e a evapotranspiração potencial, no período entre 1961 e 90;
c) risco de seca maior que $60 \%$ tomando-se por base o período entre 1970 e 1990. (SAN- TANA, 2007, p.10)

Figura 1- Nova delimitação do semiárido brasileiro.

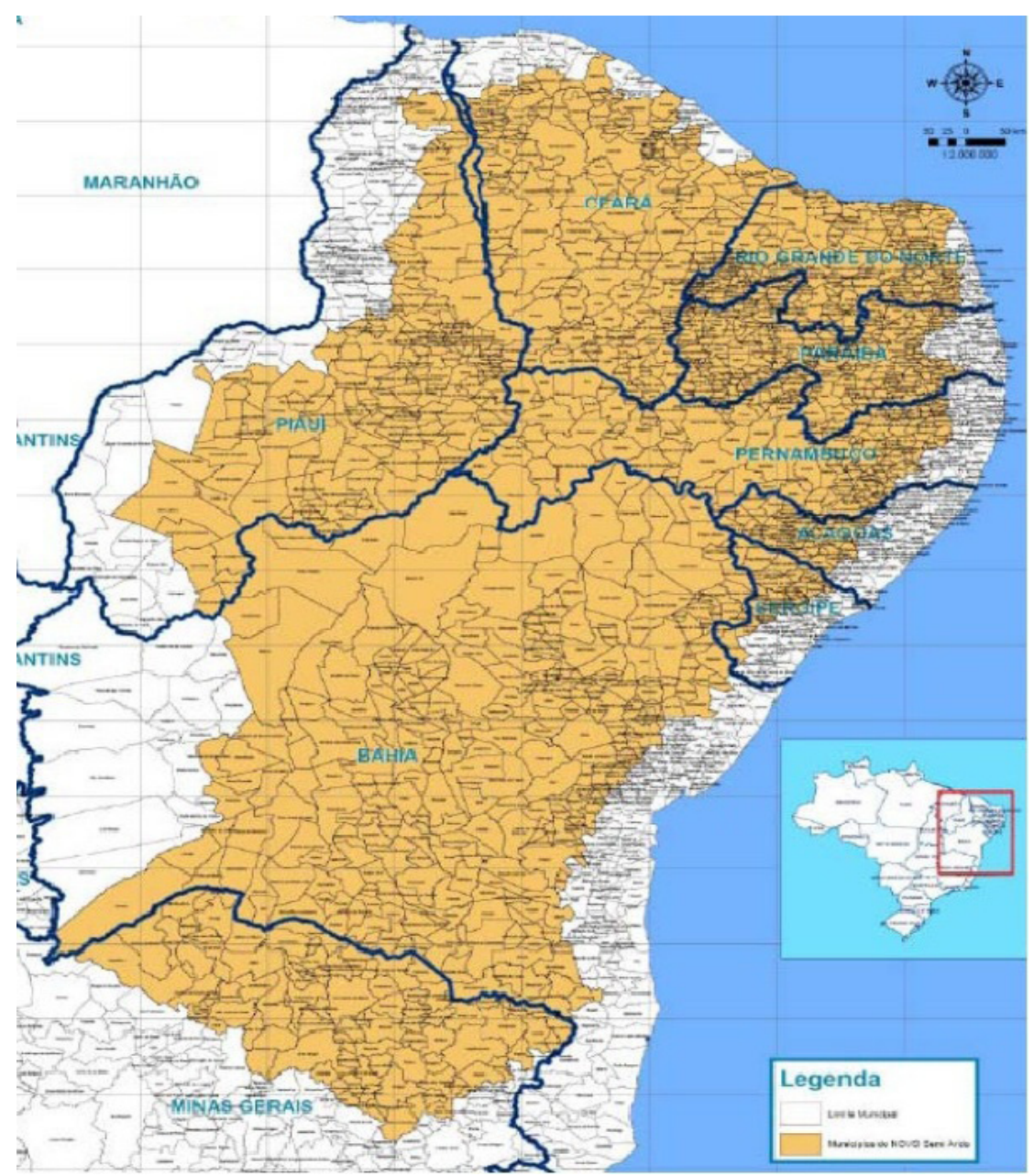

Geografia Ensino \& Pesquisa, v. 17, n.1 p. $07-14$, jan./abr. 2013 
Segundo Melo et al (2008) vale a pena ressaltar que é uma das regiões semi-áridas mais povoadas entre todas as terras secas existentes nos trópicos ou entre os trópicos, entretanto Ab'Sáber (2003) complementa a informação acrescentando que, possivelmente, se trata da região que possui a estrutura agrária mais rígida da face da Terra.

Segundo Andriguetti (2003, p. 19) apud Melo et al (2008,p.14):

\begin{abstract}
O fenômeno das secas vem sendo discutido desde o período imperial brasileiro, havendo relatos que a seca de 1877, ensejou medidas oficiais emergenciais por parte do Estado brasileiro, pois neste ano o número de mortos chegou a 500.000 pessoas. E em Fortaleza, capital do Ceará, houve uma perda de metade dos seus 120.000 habitantes.

O caso se mostrou grave e o Imperador, "sensibilizado" com a situação, prometendo ao país que se fosse necessário, utilizaria até a última jóia da Coroa para resolver o problema, de modo que nenhum nordestino morresse mais de fome.

Entretanto, tais objetos prometidos permanecem intocados em museus, e a seca, com suas conseqüências, continuou aumentando o número de suas vítimas em escala regional, expulsando milhares de camponeses que não têm acesso às poucas fontes de água usadas para alimentar o gado dos coronéis do sertão.
\end{abstract}

De acordo com Acosta (1996) apud Melo et al (2008) Como as organizações socioeconômicas e políticas não se alteraram, as secas continuam representando um dos desastres de maior proporção em escala mundial, já que geram crises econômicas e produzem calamidades sociais, concretizadas nos milhões de alistados nos programas emergenciais, o que vem se repetindo continuamente.

\title{
A questão da migração
}

As migrações internas no Brasil passam a ser mais expressivas a partir da década de 30 , nesse período que o país inicia o seu processo de industrialização e urbanização, baseado no que ficou conhecido como processo de industrialização por substituição de importações. Com isso, o Brasil deixou de ser uma economia agrário-exportadora para se tornar uma economia de bases industriais.

Nas décadas de 40 e 50 verificam-se, além das migrações para áreas urbanas desenvolvidas, fluxos migratórios direcionados às áreas de expansão de fronteira agrícola.

Todavia, a partir da década de 60 e, sobretudo da década de 70 , a expansão populacional em direção às fronteiras agrícolas atenua-se, passando os grandes aglomerados urbanos a serem o centro das atenções dos migrantes, muito disso em vista dos ritmos e dos graus diferentes de desenvolvimento verificados nas diferentes regiões.

Neste período, também se observa um forte deslocamento de população dos estados nordestinos, sobretudo de pequenos municípios e de áreas rurais, em direção à região Sudeste, especialmente para o estado de São Paulo, que apresenta um elevado nível de desenvolvimento industrial, bem como uma agricultura relativamente desenvolvida. (MEDEIROS E MOREIRA, 2008, p.2)

Para Singer (1976), os fluxos migratórios internos, "são condicionados por um processo histórico, sendo resultados de um processo global de mudança, do qual eles não devem ser separados". No caso do Brasil e de outros países latino-americanos, verificou-se uma industrialização em moldes capitalistas.

Geografia Ensino \& Pesquisa, v. 17, n.1 p. 07-14, jan./abr. 2013

Desenvolvimento local ou Migração? Uma reflexão sobre as alternativas para os jovens do semiárido brasileiro
Observa-se que quanto mais desenvolvida for a produção capitalista de um país, maior é a mobilidade exigida da força-de-trabalho. Assim, a mobilidade é uma característica do trabalhador que está submetido ao capital, ou melhor, ao modo de produção capitalista. Pode-se dizer então que a mobilidade da força de trabalho é inerente ao modo de produção capitalista, faz parte "inconscientemente" do sistema capitalista, ela é determinada pelas necessidades do capital (SINGER, 1976, p.10).

Os fatores de estagnação, o caso do semiárido brasileiro também são considerados um fator de expulsão. Que se manifestam sob a forma de uma crescente pressão populacional sobre uma 
disponibilidade de áreas cultiváveis que pode ser limitada tanto pela insuficiência física da terra aproveitável como pela monopolização de grande parte da mesma pelos grandes proprietários (SINGER, 1976).

Buscar melhoria da qualidade de vida sentir-se participante de uma sociedade que percebe 0 consumo como uma forma de expressão, de liberdade e de auto realização, são fatores que influem na busca do jovem pela realização pessoal nos grande centro urbanos, formando um grupo que aceita as condições de trabalho oferecidas e avaliam que os ganhos valem a pena.

\title{
A juventude
}

A juventude é um fenômeno social que precisa ser melhor conhecido, a sociedade precisa entender esta etapa da vida para dar respostas positivas as suas necessidades, e assim pensar políticas públicas que venham a contribuir para diminuir as ansiedades do futuro e dando condições para que eles possam ser produtivos e venham a contribuir com a construção de uma comunidade melhor.

De acordo com Karl Mannheim (1968) o problema da juventude deve ser formulado no sentido a responder a questão: qual função da juventude na sociedade? Como pode ser usado o jovem? Assim a juventude é vista como algo que pode e deve ser usado pela coletividade (MENEZES et al, 2008).

\begin{abstract}
De acordo Mannheim, não se pode falar de juventude a partir de um recorte etário, a definição de um grupo concreto no sentido da juventude passa por três diferentes aspectos: situação de geração, definida pela tendência histórica comum; a geração enquanto uma realidade, ou seja, participação em um destino comum baseado nas desigualdades sociais; e por último a unidade de geração, pois há várias maneiras de encarar a mesma situação, assim exige um pertencimento do indivíduo. Contudo Mannheim enfatiza que a condição de elemento estranho e de parte revolucionária ou conservadora vai depender das influências a qual está submetida. (MENEZES et al, 2008, p.12)
\end{abstract}

Esta percepção reforça a questão de que a juventude é um componente vital para a sociedade é representa a continuidade da espécie, e de certa forma cabe a juventude revolucionar o que precisa se revolucionado, manter o que precisa ser mantido e esse discernimento não se ensina simplesmente na sala de aula. É uma construção social, que utiliza da cultura, dos costumes, da ética e dos conhecimentos passados de geração em geração.

Desta forma, uma sociedade que não enxerga seus jovens e não oferece oportunidades para o seu desenvolvimento pode ter no futuro os resultados negativos desta falta de visão. A juventude tem buscado na cidade a melhoria da sua qualidade de vida e de um futuro melhor, formando um êxodo do rural para o urbano, sendo possível observar em algumas comunidades rurais o envelhecimento da população.

As conseqüências disso já são perceptíveis, como por exemplo: a baixa produção em algumas áreas, a dependência de benefícios sociais pagos pelo governo, o inchaço de alguns centros urbanos, o aumento da violência nas periferias das cidades, entre outros graves problemas sociais.

\section{Apresentação e análise dos dados}

O local onde ocorreu esta pesquisa, uma cidade do interior da Paraíba, se encaixa na descrição de semiárido com uma população aproximada de 10 mil habitantes, onde o principal empregador local é a prefeitura, e a principal atividade produtiva é a agropecuária. As principais culturas são o milho e o feijão, a agricultura praticada não é irrigada e esta suscetível às variações climáticas, sofrendo constantemente com as secas.

As coletas de dados aconteceram através da dinâmica do grupo focal. A atividade aconteceu em um final de semana do mês de janeiro de 2010, e a observação direta foi feita durante todo o mês através da participação do pesquisador em locais públicos como praças, feiras livres e comercio local.

Geografia Ensino \& Pesquisa, v. 17, n.1 p. 07-14, jan./abr. 2013

Sá, V. C.; Wizniewsky, J. G.

ISSN 2236-4994 11 
Para participação do grupo focal solicitou-se que a Associação comunitária local convidasse os jovens para participar de uma reunião que discutiria os problemas da comunidade. Aceitaram o convite 12 pessoas, entretanto uma tinha apenas 09 anos de idade e a outra com 39 anos. Vale destacar que elas não foram proibidas de participar das discussões. As outras pessoas estavam entre 16 e 32 anos.

No início das atividades o pesquisador se apresentou e pediu que todos também se apresentassem e dissessem o que achavam do local em que viviam, o que tinha de bom e de ruim, e o que podia ser feito para melhorar.

Com relação às coisas boas do local em que viviam, a maioria sentiu dificuldades em dizer, mas foram destacadas a tranqüilidade da cidade, a melhoria da infra estrutura da cidade, com a inauguração de praças e com a urbanização e saneamento de várias ruas.

Dentre as respostas observadas, verificou-se que o nível de escolaridade local era muito baixo, sendo que dentre os 12 participantes todos disseram que achavam necessária a melhoria do ensino local. Chegando a afirmar que para ter acesso a um ensino de melhor qualidade era necessário o deslocamento para outras cidades, distante a aproximadamente $50 \mathrm{~km}$. As dificuldades de acesso ao ensino de qualidade e a necessidade de trabalhar foram apresentados como fatores que atrapalham o desempenho no estudo dos jovens da cidade.

Durante a exposição, um jovem afirmou que o que tinha de ruim na cidade eram as lideranças políticas, e que para melhorar tinha que mudar o prefeito, ao afirmar isso vários jovens se identificaram com a resposta e acharam que o problema de fato não era o ensino de baixa qualidade, mas o desinteresse do poder público local em oferecer serviços de qualidade, tanto na educação, como saúde e lazer.

Após esta primeira rodada de conversa, pediu-se para os jovens para comentar sobre como os jovens se organizavam na cidade. As respostas indicaram que a participação dos jovens em associações estudantis, grupos de jovens da igreja, grêmios e demais formas de organização formal e informal era quase inexistente. Quando solicitados a explicar o por que dessa situação. Algumas respostas surgiram:

"O jovem daqui só quer saber de festa, não pensa nisso não".

"Falta incentivo, aqui não tem nada para a gente fazer".

"O pessoal aqui só se reúne para beber".

"Tem muito jovem que fica fora estudando e trabalhando, quando voltam a gente conversa sobre outras coisas".

$\mathrm{Na}$ terceira rodada foi perguntado se eles conheciam alguém que tinha ido morar em outro lugar, e se ele também tinham vontade de sair.

As respostas indicaram que sim, a maioria disse, inclusive, que praticamente toda família tinha alguém fora, que muita gente quando completava 18 anos ia arriscar algum tipo de serviço em outra cidade.

Com relação a vontade de sair, foi possível observar algumas respostas:

"Eu não tenho vontade de sair não, mas aqui não tem trabalho".

"Lá em casa, não querem que eu vá... tou querendo sair com os paneleiros, vender panelas, juntar dinheiro e voltar pra festa da cidade... da pra juntar um dinheirinho".

"Tenho uns conhecidos que foram trabalhar como servente de obras numa firma em São

Geografia Ensino \& Pesquisa, v. 17, n.1 p. 07-14, jan./abr. 2013

Desenvolvimento local ou Migração? Uma reflexão sobre as alternativas para os jovens do semiárido brasileiro disse que o salário é $R \$ 1200,00$ e a comida e dormida é por conta da empresa... Se tiver vauga para mim lá eu vou..."

No final da reunião, foi perguntado para os participantes o que eles tinham achado da atividade, eles disseram que tinha sido boa e que gostariam que tivesse mais reuniões. Como encaminhamentos, ficou o desafio deles continuarem a ser reunir e que criassem espaços para a participação dos jovens na associação. 


\title{
Considerações finais
}

Diante dos relatos obtidos e das observações feitas é possível verificar que para o grupo de 12 jovens que participaram da reunião, as principais mudanças para a melhoria da cidade não dependem deles, e sim de quem esta exercendo o poder executivo municipal.

Também é possível observar que a solução de buscar algo melhor em outra cidade ou região é aceita normalmente, pois é fato comum, a maioria das famílias ter alguém que esta morando fora.

Com relação ao tempo de permanência fora, ninguém deixou clara a intenção de passar a morar fora definitivamente, a maioria disse que gostaria de passar só um tempo fora, o suficiente para juntar dinheiro e adquirir algo. Como uma moto, por exemplo, ou gado, ou simplesmente ter dinheiro para ir as festas de fim de ano.

Diante desse fato, algumas reflexões podem ser feitas, os jovens ao passar parte do ano trabalhando fora das suas comunidades, trazem dinheiro, mas não aplicam sua energia transformadora no local de origem e sim em outras cidades, ou outras regiões que fazem uso desta mão de obra, geralmente mais barata, para maximizar seus ganhos.

\begin{abstract}
A demanda por força de trabalho, o mais influente fator de atração, composta tanto pela demanda gerada pelo setor industrial bem como pelo setor de serviços (prestados tanto em âmbito privado como no governamental), "de maneira geral é interpretada como oportunidade econômica". Esta se torna atraente a partir do momento em que é oferecida uma remuneração melhor no lugar de "destino" do que no lugar onde o futuro migrante reside. (SINGER, 1976, p.13)
\end{abstract}

Esta forma de migração sazonal obedece uma lógica de exercito de reserva, que atende as necessidades das empresas capitalistas em momentos específicos, de modo a equilibrar os preços do custo de mão de obra e maximizar os lucros sempre que for de interesse das empresas.

Por fim, vale ressaltar que o fenômeno das migrações traz conseqüências para as regiões de saída e chegada, e por isso é importante observar, principalmente nos locais de saída, o que este fenômeno significa para o desenvolvimento do local, se existem implicações para o futuro da região o fato da mão de obra jovem estar sendo utilizada em outra região.

Ao que parece o dinheiro que retorna ou que é enviado pelos migrantes amenizam a situação durante um curto espaço de tempo, mas a perda de jovens resulta em um prejuízo muito maior para a cidade a médio e longo prazo, favorecendo a manutenção de estruturas arcaicas que tanto prejudicam a região.

\section{Referências}

ARMANDO, C. et al. Los Métodos Del Diagnóstico Rural Rápido Y Participativo. Curso de Diagnóstico Rural Participativo El Rincón de Ademuz, 1998.

FREIRE, P. Pedagogia do oprimido. São Paulo: Paz e Terra, 1996.

GRANJEIRO, J. P. e FERNANDES, M. J. C. Principais Desafios Da Educação Do Campo: Um Estudo Da Comunidade Vila Perímetro Irrigado De Pau Dos Ferros/ Rn. Anais Encontro Regional SOBER Nordeste, Mossoró, 2008

CORDEIRO NETO, J. R. E ALVES, C. L. B. A Relação Entre Escola E Território Na Promoção Do Desenvolvimento Local: Implicações Para As Políticas Educacionais. Anais Encontro Regional SOBER Nordeste, Mossoró, 2008

Geografia Ensino \& Pesquisa, v. 17, n.1 p. 07-14, jan./abr. 2013

Sá, V. C.; Wizniewsky, J. G. 
MELO, J. A. B; PEREIRA, R. A.; NETO, J. D. Atuação do estado brasileiro no combate à seca no nordeste e ampliação das vulnerabilidades locais. Anais do II Semiluso- Seminário Luso Brasileiro sobre agricultura familiar e desertificação, João Pessoa, 2008

MENEZES, M. et al. As Perspectivas De Migrações De Jovens Rurais Do Estado Da Paraíba. Anais do 2 semiluso, João Pessoa, 2008

PATARRA, N. Tendências e modalidades recentes das migrações internas e da distribuição populacional no Brasil: um olhar para o Nordeste. In: Seminário Quantos Somos e Quem somos no Nordeste. Recife: 2003.

SANTANA, M. O. (org.) Atlas das áreas susceptíveis à desertificação do Brasil. Brasília: MMA/SRH/UFPB, 2007

SINGER, P. I. Economia política e urbanização. 4.ed. São Paulo: Brasiliense, 1976.

TARGINO, I; MOREIRA, E. Migrações sazonais e saúde do trabalhador. João Pessoa: Travessia, v. 7, n. 20, 1994.

VERDEJO, M. Diagnóstico Rural Participativo: Guia Prático. Brasília: MDA, 2006

MEDEIROS, E. R; MOREIRA, I.T. Expectativas de jovens rurais quanto à migração o caso de Cacimba de Dentro/PB. Anais do II Semiluso- Seminário Luso Brasileiro sobre agricultura familiar e desertificação, João Pessoa, 2008

SILVA, S. R. A. Migração para o trabalho na "sulanca" uma solução ou um problema para os trabalhadores rurais? Anais do II Semiluso- Seminário Luso Brasileiro sobre agricultura familiar e desertificação, João Pessoa, 2008

\section{Correspondência:}

Vinícius Claudino de Sá- Rua Osório Queiroga de Assis, no. 130, Bessa, João Pessoa-PB, CEP 58035-050

E-mail: viniciusclaudino@gmail.com

Recebido em 18 de abril de 2012.

Revisado pelo autor em 13 de setembro de 2012.

Aceito para publicação em 01 de outubro de 2012. 